\title{
The Viscosity Testing on the Blending of HSD with PPO for Eligibility Criteria of Gas Turbine Fuel as the Renewable Energy Solution
}

\author{
Tedy Harsanto ${ }^{\mathrm{a} *}$, Feti Eka Rahayu ${ }^{\mathrm{a}}$ \\ ${ }^{a}$ Department of Physics, Faculty of Mathematics \& Natural Science, State University of Jakarta, Jakarta, Indonesia \\ Jln. Pemuda No. 10 Rawamangun, Jakarta Timur 13220, Indonesia
}

\begin{abstract}
The viscosity of vegetable oils palm oil in particular olein is 18 times higher than the viscosity of HSD. Whereas, the viscosity is allowable for the gas turbine engines which is around 0 to $10 \mathrm{CSt}$ at the maximum temperature of $50{ }^{\circ} \mathrm{C}$ or when converted to the dynamic viscocity of about 0.78 to $780 \mathrm{mPa}$.s. In order to meet the gas turbine criteria, so that done the blending between the samples of HSD with PPO and then heated. From the blending of $95 \% \mathrm{HSD}-5 \%$ PPO at the temperature range of $30^{\circ}-35{ }^{\circ} \mathrm{C}$ were obtained the viscocity value with an average of 3,43 mPas. That results show that the viscosity value of the blending between HSD with PPO still meets the standards of eligibility as a gas turbine fuel.
\end{abstract}

Keywords: Gas turbine; HSD; PPO; temperature; viscosity.

\section{Introduction}

PPO (Pure Plant Oil) is a fuel derived from vegetable oils. Based on the reference, obtained that the value of viscosity of PPO in $40{ }^{\circ} \mathrm{C}$ is range between $30 \mathrm{CSt}$ to $50 \mathrm{CSt}$. HSD (High Speed Diesel) fuel is coming from fossil oil. The value of its viscocity is range from (2 to 5) CSt at $40{ }^{\circ} \mathrm{C}$.

The content of energy on PPO depending from its type. Basically, PPO has the heat value less than $5 \%$ from the heat value of FUEL diesel.

To avoid the influence of impurities in the process of combustion in the gas turbine engines, PPO must be purified before.

Pure plant oil (PPO) can be mixed with HSD/diesel oil to be used as a fuel gas turbine engine on a particular mixture. After filtration, the blend of fuels need to be heated to reduce viscosity of its alloy so that the fog process that occur in the combustion chamber can be perfect.

The burning using PPO is very useful for the environment because the PPO that replaces diesel FUEL/HSD system resulted in becoming neutral carbon.

\footnotetext{
* Corresponding author. Mobile phone.: +62 83874130449

E-mail address: tedy.harsanto@gmail.com ; tmail_gender@yahoo.com
} 


\section{Methods}

The viscosity test aims to find out the default value from the sample blending results as eligibility on gas turbine fuel specifications. Measurement begins with doing a calibration on the viscometer then conducted sampling HSD $100 \%$, PPO $100 \%$ and sample blending results in the two hours firstly. Then on each sample measurement, the temperature is set according to the magnitude of the temperature used in the blending system that aims to make the state of the same temperature of sample during the process of blending is done so it can know the value of viscosity of the sample results of the eligibility level for blending on specification for gas turbine fuel. On the testing, the viscosity of sample values recorded at a temperature of $30{ }^{\circ} \mathrm{C}$ and $35{ }^{\circ} \mathrm{C}$ adjust the temperature that is used on the running blending system of HSD - PPO.

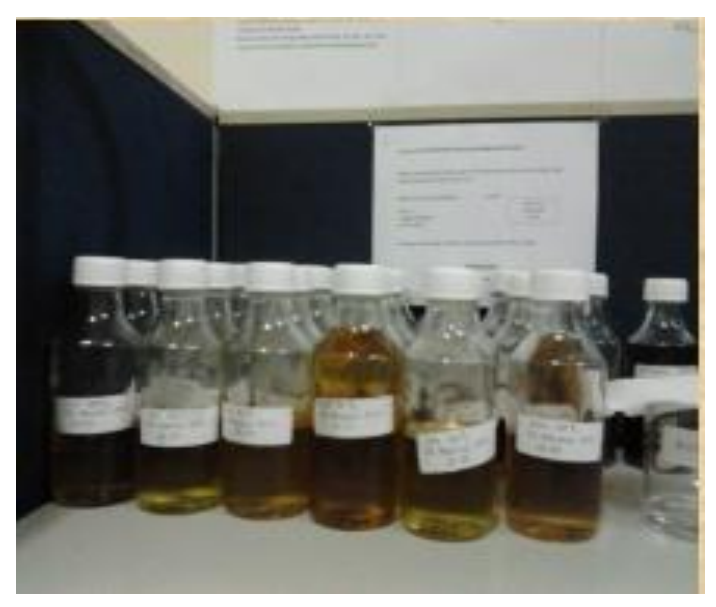

Fig. 1. The blending samples of HSD - PPO.

\section{Result and discussion}

The first testing is a sample of $100 \%$ pure HSD. On this test was obtained the viscosity value of HSD is 3.16 $\mathrm{mPas}$ at a temperature of $30{ }^{\circ} \mathrm{C}$. On the next test is the blending sample with the composition of $95 \%$ HSD and $5 \%$ PPO was obtained the viscocity with an average value of $3.44 \mathrm{mPas}$ at a temperature of $30{ }^{\circ} \mathrm{C}$ and $3.00 \mathrm{mPas}$ at a temperature of $35{ }^{\circ} \mathrm{C}$. And the third test is the blending sample with a composition of $90 \%$ HSD and $10 \%$ PPO was obtained the viscocity is $3.88 \mathrm{mPas}$ at a temperature of $30{ }^{\circ} \mathrm{C}$ and $3.35 \mathrm{mPas}$ at a temperature of $35{ }^{\circ} \mathrm{C}$. 


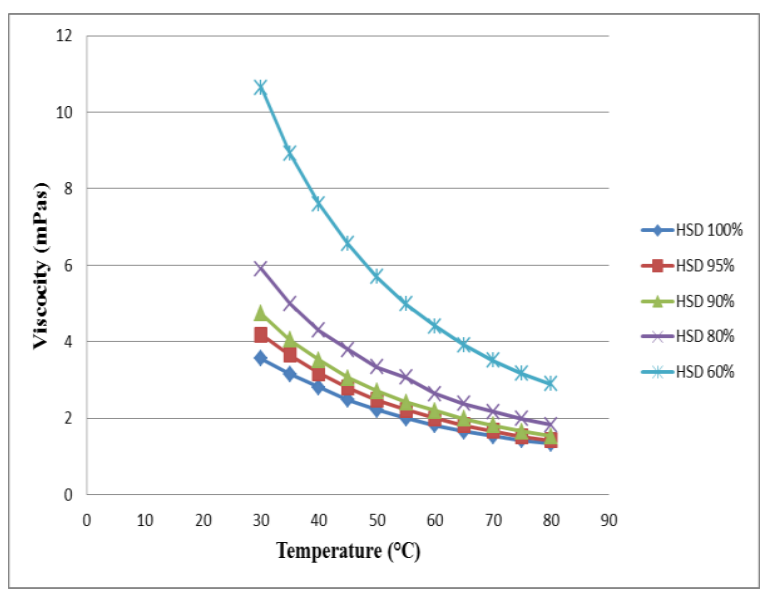

(a)

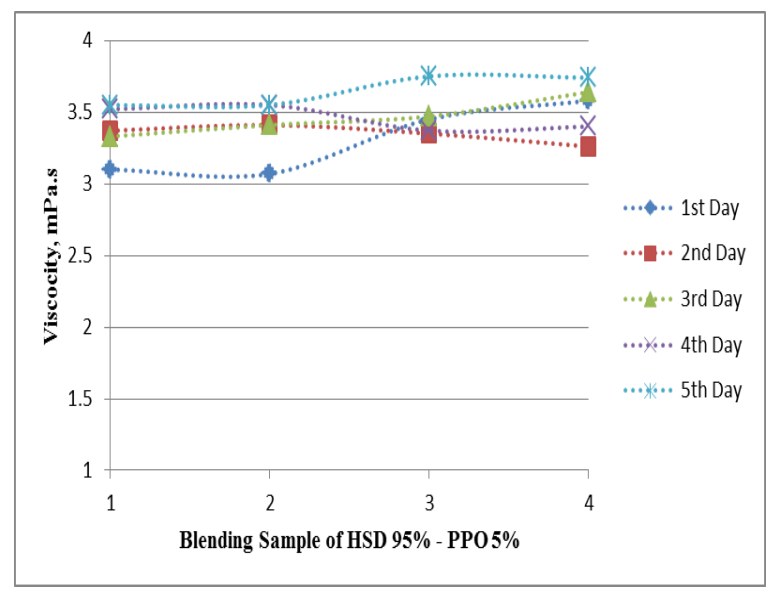

(b)

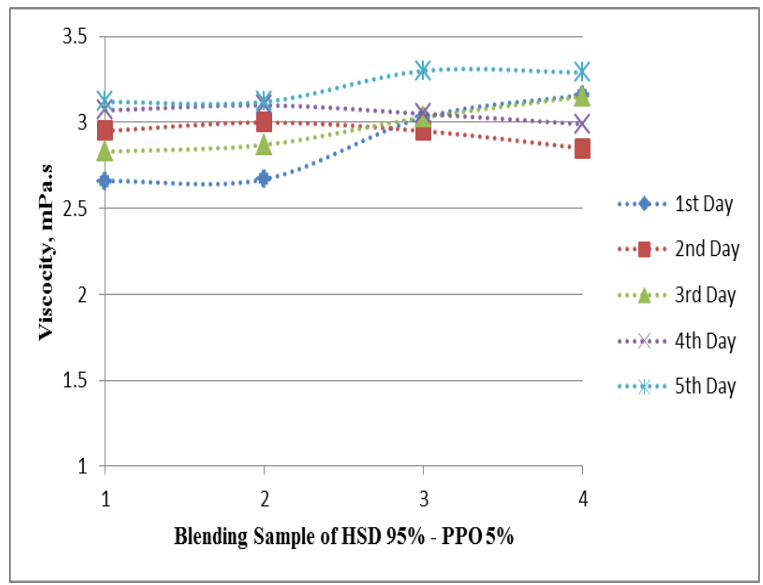

(c)

Fig. 2. (a) The influence of temperature to the dynamic viscocity value of the HSD - PPO blending;

(b) The dynamic viscocity value of the $95 \% \mathrm{HSD}-5 \% \mathrm{PPO}$ at the $30{ }^{\circ} \mathrm{C}$;

(c) The dynamic viscocity value of the $95 \% \mathrm{HSD}-5 \%$ PPO at the $35{ }^{\circ} \mathrm{C}$.

\section{Conclusion}

The parameter of viscosity is useful for determining the success of the burning system. The test results performed on the viscosity of HSD - PPO blending is measured on a scale of $30{ }^{\circ} \mathrm{C}$ to $35{ }^{\circ} \mathrm{C}$ adjust the temperature with the temperature used in the blending system. It is intended that the viscosity is stayed at a temperature that range to maintain the viscosity value is less than the limit set by the entrance of the viscosity of a gas turbine engine.

\section{Acknowledgements}

The authors are thankful to BPPT Thamrin Jakarta especially for Center of Technology and Energy Resources Development Team for support of facilities in this research. 


\section{References}

[1] A\&D Company Limited. SV-10 SV-100 Vibro Viscometer Instruction Manual; 2008.

[2] Chin JS, Lefebvre AH, ASME Journal of Engineering for Gas Turbines and power 117:266-271; 1995.

[3] Leung DYC, Koo BCP, Guo Y. Degradation of biodiesel under different storage conditions. Bioresource Technology 2006 ; 97,250 - 256.

[4] Bozbas K. Biodiesel as an alternative motor fuel: Production and policies in the European Union. Renewable \& Sustainable Energy Reviews $2005 ; 1-12$.

[5] Conceição, MM, Candeia RA, Dantas HJ, Soledade LE.B, Fernandes, Jr., VJ, Souza AG. Rheological Behavior of Castor Oil Biodiesel. Energy \& Fuels 2005; 19, $2185-2188$. 